\title{
PENYELENGGARAAN COMMUNITY CERTIFICATION AUTHORITY \\ UNTUK PENGAMANAN SUMBER DAYA INTERNET OLEH KOMUNITAS UNTUK KESIAPAN ASEAN REGIONAL E-COMMERCE
}

\author{
Edmon Makarim ${ }^{1}$
}

\begin{abstract}
Indonesia should immediately establish a public key infrastructure to facilitate the use of digital signatures by the public, in particular to facilitate the public service. This is to accommodate the growing practice of the network reliability (web of trust) and multi-identity. To embody Community CA Indonesia, necessary legal research tinged with shades of interdisciplinary. Train of thought that the background for this research topic selection is the gap between law and technology dynamics, especially in the implementation of electronic security systems. Generally arranged that each Trust Services Providers have the responsibility and legal obligations are adhered to the imposition of proof. Technically the term Community CA does not have a standardized definitions, but usually addressed to the implementation of the CA to the benefit of both communities is done by giving a certificate for free or paid and technically embrace web-trust application.
\end{abstract}

Keywords: community CA, public services, e-government

\begin{abstract}
Abstrak
Indonesia harus segera membangun infrastruktur kunci publik guna memfasilitasi penggunaan tanda tangan digital oleh masyarakat, khususnya untuk memfasilitasi pelayanan publiknya. Hal ini untuk mengakomodir praktek yang tengah berkembang terhadap jejaring keterpercayaan (web of trust) dan multi-identity. Untuk menjelmakan Community CA Indonesia, perlu dilakukan penelitian hukum yang diwarnai dengan corak interdisipliner. Alur pikiran yang melatar belakangi pemilihan topik riset ini adalah adanya kesenjangan antara dinamika hukum dan teknologi khususnya dalam penyelenggaraan sistem keamanan secara elektronik. Secara umum diatur bahwa setiap Trust Services Providers memiliki tanggung jawab dan kewajiban hukum yang menganut pembebanan pembuktian terbalik. Secara teknis istilah Community CA belum mempunyai suatu batasan pengertian yang baku, namun lazimnya di alamatkan kepada penyelenggaraan CA untuk kepentingan komunitas baik yang dilakukan dengan memberikan certificate secara gratis maupun berbayar dan secara teknis menganut penerapan web-trust.
\end{abstract}

1 Dosen Inti Penelitian Bidang Hukum Telematika FHUI. Alamat kontak; edmon_makarim@yahoo.com. 
Kata kunci: community CA, pelayanan publik, e-government

\section{Pendahuluan}

Menjelang ASEAN Community $2015,^{2}$ terdapat berbagai tantangan bagi bangsa dan negara Indonesia untuk mempersiapkan beberapa hal penting terkait perkembangan Teknologi Informasi dan Komunikasi ("TIK"), khususnya terkait ASEAN ICT Master Plan 2015 dan Master Plan on ASEAN Connectivity. ${ }^{3}$ Selain kemungkinan akses pelayanan publik lintas negara sesama anggota ASEAN, salah satunya konsekwensi lainnya adalah semaraknya perdagangan secara elektronik dalam kawasan ASEAN (regional e-commerce). Salah satu hal penting dalam e-commerce adalah aspek keamanannya khususnya untuk kejelasan identitas digital secara online, yang salah satu teknologinya adalah penggunaan tanda tangan elektronik. Salah satu dari tanda tangan elektronik yang cukup relatif mapan adalah tanda tangan digital (digital signature) yang ditunjang dengan sertifikat digital (digital certificate) yang diterbitkan oleh penerbit sertifikat digital (Certification Authority/" $C A$ ") $)^{4}$ berikut penyelenggaraanInfrastruktur untuk kunci publik,

2 The ASEAN Economic Community (AEC) shall be the goal of regional economic integration by 2015. AEC envisages the following key characteristics: (a) a single market and production base, (b) a highly competitive economic region, (c) a region of equitable economic development, and $(d)$ a region fully integrated into the global economy. The AEC areas of cooperation include human resources development and capacity building; recognition of professional qualifications; closer consultation on macroeconomic and financial policies; trade financing measures; enhanced infrastructure and communications connectivity; development of electronic transactions through e-ASEAN; integrating industries across the region to promote regional sourcing; and enhancing private sector involvement for the building of the AEC. In short, the AEC will transform ASEAN into a region with free movement of goods, services, investment, skilled labour, and freer flow of capital. B.6. E-commerce: To lay the policy and legal infrastructure for electronic commerce and enable on-line trade in goods (e-commerce) within ASEAN through the implementation of the e-ASEAN Framework Agreement and based on common reference frameworks: Actions: (i) Adopt best practices in implementing telecommunications competition policies and fostering the preparation of domestic legislation on e-commerce; (ii) Harmonise the legal infrastructure for electronic contracting and dispute resolution; (iii) Develop and implement better practice guidelines for electronic contracting, guiding principles for online dispute resolution services, and mutual recognition framework for digital signatures in ASEAN; (iv) Facilitate mutual recognition of digital signatures in ASEAN; (v) Study and encourage the adoption of the best practices and guidelines of regulations $v$. and/or standards based on a common framework; and (vi) Establish a networking forum between the businesses in ASEAN and its Dialogue Partners as a platform for promoting trade and investment. (huruf tebaldan garis bawah dari penulis)

${ }^{3}$ Lihat e-ASEAN Framework Agrement and ICT Master Plan: [the four objectives of the e-ASEAN Framework Agreement, namely (a) to develop, strengthen and enhance the competitiveness of the ICT sector; (b) reduce the digital divide within and amongst ASEAN Member Countries; (c) promote cooperation between the public and private sectors; (d) develop ASEAN Information Infrastructure. 
baik bagi pemerintah (government root $C A$ ), pelaku usaha (private root $C A$ ) dan juga masyakarakat (community $C A$ ).
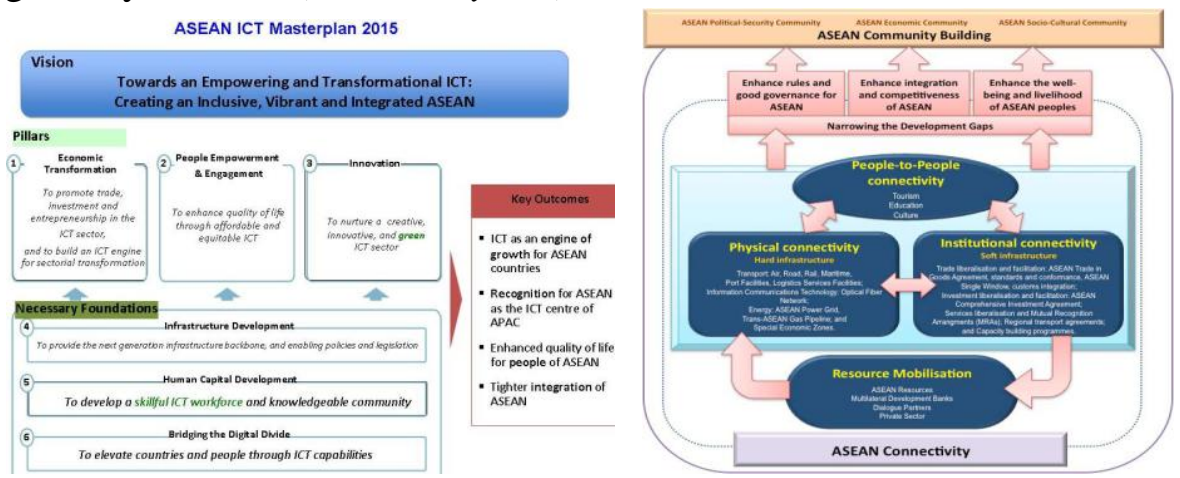

Figure I.1: Interaction between ASEAN Connectivity and ASEAN Community Source: Modified from ERIA

Dengan tujuan untuk penyiapan hukum dan kebijakan dalam jangka pendek dan jangka panjang. Dalam jangka pendek dan menengah Indonesia harus segera membangun infrastruktur kunci publik guna memfasilitasi penggunaan tanda tangan digital oleh masyarakat, khususnya oleh Negara dalam memfasilitasi pelayanan publiknya. Dalam jangka panjang, Indonesia seharusnya dapat menjadi "trusted network" agar eksis dan tumbuh menjadi pemain dominan di kawasan. Berbekal letak geografis dan jumlah populasi yang lebih dari 230 juta penduduk, Indonesia adalah pangsa pasar yang besar dan mempunyai pengaruh yang signifikan dalam kawasan. Kehandalan dan Keamanan infrastruktur dan sistem aplikasi di Indonesia akan menjadi nafas bagi kelancaran roda ekonomi ASEAN, karenanya dibutuhkan kesiapan sistem hukum nasional yang kokoh untuk itu.

Dengan penelitian ini diharapkan terbentuknya hukum dan kebijakan yang akan diperoleh dari penelitian secara bertahap. Target penelitian kali ini

${ }^{4}$ Certification Authority atau Certification Service Provider adalah penyelenggara sistem elektronik yang menerbitkan suatu sertifikat elektronik yang menjelaskan informasi tentang identitas suatu subyek hukum dan/atau perangkatnya. Sertifikat tersebut juga dapat memuat keberadaan suatu tanda tangan elektronik yang digunakan sebagai alat untuk melakukan verifikasi atau autentikasi secara elektronik.

[CAor "TrustedThirdParty": Anentity (typically acompany) that issues digital certificates too the rentities (organizations or individuals) to allow them to prove their identity to others. A Certificate Authority might be an external company (such as Veri Sign) that offers digital certificate services or they might be an internal organization such as a corporate MIS/IT's department. The Certificate Authority's chief function is to verify the identity of entities and issue digital certificates at testing to that identity. The process uses public key cryptography to create "network of trust". If I want to prove my identity to you, I ask a CA (who you trust to have verified my identity) to encrypt a hash of my signed key with their private key. Then you can use the CA's public key to decrypt the has hand compare it with a hash you calculate your self. Hashes are used to decrease the amount of data that needs to be transmitted. The hash function must be cryptographically strong, e.g. MD5. <http://home.netscape.com/comprod/server_central/support/faq/certificate_faq.html\#11>. (1998-03-30) The Free On-line Dictionary of Computing, (C) Denis Howe 2010 <http://foldoc.org> 
adalah pengembangan kerangka hukum dan kebijakan terhadap kemungkinan penyelenggaraan Community $C A$ di Indonesia. Sesuai reformasi hukum, selain pembangunan CA Pemerintah, faktanya masyarakat tetap memerlukan adanya Community $C A$ sebagai alternatif pendukung. Selain menjadi sarana pembelajaran dan pemberdayaan masyarakat terhadap pengamanan informasi dan komunikasi elektronik, Community $C A$ berikut Root-nya juga dapat menjadi wadah konsolidasi dan interoperabilitas dari berbagai CA yang telah dibentuk sebelumnya, khususnya oleh para akademisi dan para pelaku usaha di kawasan.

Dengan melakukan penelitian kwalitatif terhadap norma hukum yang berlaku dan dengan mencermati best practices ataupun praktek bisnis yang berkembang dalam penerapan Community $C A$. Hasilnya akan diperoleh keluaran berupa kerangka hukum dan kebijakan serta usulan regulasi berikut model dan kerangka kerja operasional ("trusted framework") terhadap penyelenggaraan Community $C A$ yang saling interoperablesesuai dengan karakteristik perkembangan $\mathrm{CA}$ Indonesia. Indonesia berpeluang menjadi jembatan (bridge) bagi semua CA di ASEAN mengingat sektretariat ASEAN berada di Indonesia.

Alur pikiran yang melatarbelakangi pemilihan topik riset ini adalah adanya kesenjangan antara dinamika hukum dan teknologi khususnya dalam penyelenggaraan sistem keamanan secara elektronik. Dalam reformasi, sistem hukum nasional telah berkembang pesat. Indonesia telah mempunyai berbagai ketentuan hukum terkait e-Government dan e-Commerce, namun sayangnya hal tersebut tampak masih belum terjahit rapih konsistensinya secara sempurna dan utuh. Beberapa peraturan perundang-undangan telah diundangkan namun harmonisasi dan sinkronisasi satu dan lainnya harus tetap senantiasa ditingkatkan, antara lain; Inpres No.6 Tahun 2001 tentang Kebijakan Telematika Nasional, Inpres No.3 tahun 2003 tentang e-government, UU No.11 tahun 2008 tentang Informasi dan Transaksi Elektronik, UU No.14 tahun 2008 tentang Keterbukaan Informasi Publik, UU 25 Tahun 2009 tentang Pelayanan Publik, UU 43 Tahun 2009 tentang Arsip, UU No.3 Tahun 2004 tentang Perindustrian, UU Perdagangan serta UU No.24 Tahun 2013 tentang revisi Administrasi Kependudukan dan UU No.2 Tahun 2014 tentang revisi Jabatan Notaris, dan dalam waktu dekat akan segera menyusul RUU Administrasi Pemerintahan.

Sebagai negara hukum modern terbesar di ASEAN, Indonesia telah menjadi contoh dalam berdemokrasi dan pemilihan langsung serta keterbukaan informasi untuk penerapan tata kelola yang baik dalam segala bidang. Demikian pula halnya dengan Internet Governance, Indonesia adalah salah satu negara kawasan yang terbukti tidak otoriter dan telah menggalang harmonisasi dari berbagai kepentingan dari multi-stakeholders sebagai terlihat dalam Internet Governance 2013 di Bali yang lalu.

Dalam konteks pengamanan sumber daya internet (IP Address dan Domain Name) dan kerangka sistem keautentikan nasional, maka selain penyelenggaraan Government Root Certification Authority oleh Pemerintah untuk akses pelayanan publik, maka bangsa Indonesia masih memerlukan suatu 
alternatif jika terjadi sesuatu pada CA pemerintah. Oleh karena itu diperlukan Private dan/atau Community Root $C A$ yang bersifat mendukung dan komplementer dari sistem yang dibangun pemerintah, khususnya untuk interoperabilitas dalam konteks communitiy $C A$ secara nasional, regional maupun mancanegara. Hal ini untuk mengakomodir praktek yang tengah berkembang terhadap jejaring keterpercayaan (web of trust) dan multi-identity. Diantaranya adalah keberadaan Pretty Good Privacy ("PGP"), CA cert.org. dan juga Open Identity Exchange ("OIX"). Hal tersebut menjadi obyek kajian penelitian ini, karena setidak-tidaknya keberadaan Community $C A$ adalah menjadi sarana pemberdayaan masyarakat untuk mengamankan informasi dan transaksinya sendiri via Internet dan membiasakan diri dalam penggunaan kriptografi nasional. Lebih jauh, hal tersebut juga dapat menjadi wadah harmonisasi bagi keberagaman identitas elektronik (multiple/federated identity) yang telah ada.

Untuk menjelmakan Community $C A$ Indonesia, perlu dilakukan penelitian hukum yang diwarnai dengan corak interdisipliner. Keterlibatan mitra peneliti dari berbagai disiplin ilmu yang lain dalam wadah klaster telematika ini, tentunya akan melengkapi aspek teknis dan manajemen penyelenggaraannya. Dengan jejaring mitra kolaborasi riset klaster telematika yang telah terjalin selama ini, Community $C A$ akan menjadi perhatian bersama dan akan digunakan demi kepentingan bersama. Hal ini dalam prakteknya sangatlah mendesak karena sangat diperlukan demi mengisi kekosongan yang terjadi sekarang ini, akibat proyek pembangunan CA pemerintah yang ternyata masih belum kunjung rampung. Pada sisi yang lain, demi keamanan, sebenarnya dibutuhkan suatu penyikapan yang relatif cepat. Meskipun hal tersebut belum sempurna, namun prakteknya akan dapat digunakan oleh masyarakat, demi mendorong kesadaran (awareness) masyarakat itu sendiri dalam mengamankan informasi dan komunikasi elektroniknya.

\section{Rumusan Permasalahan}

Terdapat beberapa permasalahan penting berkaitan dengan fakta tersebut diatas. Pertama, bagaimanakah fungsi dan peran Community $C A$ yang telah ada baik internasional maupun nasional. Kedua, dengan keberadaan UU ITE dan PP-PSTE sebenarnya terbuka peluang Community $C A$ di masyarakat yang belum terkonsolidasi kepada satu induk ataupun satu akar secara nasional yang karenanya diperlukan suatu kerangka hukum untuk menjamin interoperabilitas satu CA dengan CA yang lainnya (mesh community CA). Pada dasarnya, sesuai dengan sistem hukum yang berlaku, masih sangat terbuka kemungkinan terbentuknya Community Root CA melengkapi government Root CA. Faktanya, dinamika teknis untuk Govenrment $C A$ tesebut masih belum terlihat dengan jelas oleh publik, sementara terbukanya kemungkinan pemberdayaan beberapa CA universitas yang dapat tumbuh secara sporadis juga belum terjalankan dengan baik. Sementara kegiatan Private $C A$ pun baik domestic maupun asing prakteknya sudah digunakan oleh komunitas perbankan Indonesiameskipun 
belum terpetakan dengan baik, ia telah digunakan walau belum terdaftar, belum tersertifikasi ataupun belum terakreditasi di Indonesia.

Berdasarkan fakta tersebut di atas, maka keutamaan dari riset ini adalah ntuk mendorong terbentuknya Community Root CA Nasional. Tujuan umum yang membuat hal tersebut sangat diperlukan adalah untuk kesiapan masyarakat dan bangsa Indonesia sendiri dalam menyongsong ASEAN Community 2015. Sedangkan tujuan khusus dari penelitian ini adalah bahwa sekiranya pemerintah belum berhasil membangun National Root CA, maka masyarakat masih dapat difasilitasi oleh keberadaan Community $C A$ yang saling terkonsolidasi demi pengamanan swadaya mereka sendiri.

\section{Sumber Daya Internet}

Umumnya yang dikenal sebagai sumber daya Internet ada hal, yakni; (i) IP address, (ii) Nama Domain. Sementara jika kita amati lebih jauh sumber daya yang tak terpisahkan adalah keberadaan setiap data dan/atau informasi yang melintasi internet, khususnya Data Pribadi setiap orang yang melakukan transaksi.

Dalam tata kelola internet, ketentuan hukum yang berlaku ialah hukum komunitas. Pemerintah tidak memiliki kewenangan untuk melakukan pengaturan IP Address dan Nama Domain oleh karena itu dikenal kaedah ketentuan yang self-regulatory. Demikian pula keberadaan sistem pencatatan pengalamatan IP dan Nama Domain. Semula pengelolapencatatan nama domain diselenggarakan oleh NSI Inc dan nama domain dikelola oleh IANA kemudian keduanya dikelola oleh ICANN. Selanjutnya kedua resources tersebut didelegasikan kepada komunitas yang ada dengan model per blok.

Sedikit berbeda dengan ketentuan generic Top Level Domain (Nama Domain tingkat tinggi), maka khususnya Nama Domain dengan Kode (country code TLD) tentunya tidak akan dapat melepaskan keberadaan suatu Negara dan Pemerintahnya. Pertanyaan siapakah yang berdaulat atas data tersebut, seringkali dikemukakan?

\section{Sistem Keautentikan Secara Elektronik}

Pembicaraan tentang penyelenggaraan sistem dan transaksi elektronik tidak akan pernah lepas dari sistem keotentikan secara elektronik (eauthentication). Dalam memanfaatkan internet sebagai suatu medium utama $e$ government dan e-commerce, terlebih dalam pelayanan publik dan perolehan Big Data serta Cloud Computing, maka kejelasan kerangka keterpercayaan ("trusted framework") merupakan suatu hal utama yang harus sangat diperhatikan oleh penyelenggara sistem elektronik, baik pemerintah maupun swasta. Kerangka Hukum untuk Jaminan Keterpercayaan menjadi suatu hal yang tidak dapat dipisahkan dari suatu sistem komunikasi elektronik khususnya internet yang merupakan medium komunikasi yang lebih menawarkan kecepatan bukan keamanan (Unsecured communication). Internet adalah suatu 
jaringan computer yang terdistribusi yang pengiriman pesan didalamnya adalah sebagaimana layaknya pengiriman paket pesan secara berantai (Transmission Control Protocol/Internet Protocol). Agar suatu pesan aman maka kata kuncinya terletak pada sistem pengamanan informasinya yang umumnya menggunakan teknologi tanda tangan elektronik, khususnya tanda tangan digital yang menggunakan produk kriptografi dengan algoritma asimetris yang didukung dengan penyelenggaraan infrastruktur pasangan kunci public serta sertifikat elektronik.

Untuk memastikan keamanan terhadap informasi dan transaksi dalam pelaksanaan pelayanan publik melalui sistem elektronik maka harus ada suatu sistem secara nasional yang dapat menjelaskan sistem keautentikan tersebut. Penyelenggaraan sertifikat elektronik yang mendukung tanda tangan elektronik untuk memverifikasi dan mengotentikasi para pihak, baik penyelenggara maupun pengguna layanan bahkan dokumen dan sistem perangkat serta jaringannya, adalah hal yang tak dapat ditampik lagi urgensinya sekarang ini. Sesuai literatur, sistem keautentikan tersebut umum dikenal sebagai "national e-authentication." Hal tersebut pada prakteknyajuga sangat bergantung kepada validitas sistem identitas subyek hukum, khususnya pengelolaan data kependudukan dan sistem administrasi kependudukan yang telah ada (national registry) berikut interoperabilitas fungsinya dengan berbagai macam urusan atau pemanfaatan dalam kehidupan berbangsa dan bernegara.

Mengacu kepada hasil penelitian dari OECD dan UNCITRAL $^{5}$ maka dapat dipahami pengertian teknis tentang sistem keautentikan tersebut. UNCITRAL mencermati setidaknya terdapat beberapa model kebijakan dalam penyelenggaraan Tanda Tangan Elektronik ("TTE") dan sertifikat elektronik yang mendukung TTE tersebut. Pada dasarnya, dapat dibedakan adanya tiga pendekatan dalam pengaturan tentang TTE, khususnya dengan melihat kekuatan pembuktian dari suatu informasi elektronik, yakni: (1) minimalist approach (functional equivalent approach); (2) technology specific approach, dan (3) two-tiered or two-pronged approach. Ketiga pendekatan tersebut akan menjadi acuan dalam membuat kebijakan publik suatu negara tentang sistem keautentikan dalam konteks pengakuan nilai hukum pembuktiannya. ${ }^{6}$

\begin{tabular}{|l|c|}
\hline \multicolumn{1}{|c|}{ OECD } & UNCITRAL \\
\hline $\begin{array}{l}\text { Authentication can mean a variety of things } \\
\text { depending on the context in which the term } \\
\text { is used. An Internet search on the term } \\
\text { "authentication" yields a very broad range } \\
\text { of definitions, some addressing }\end{array}$ & $\begin{array}{l}\text { Authentication in Context } \\
\text { In some cases, the expression "electronic } \\
\text { authentication" is used to refer to techniques } \\
\text { authentication of persons or other entities, } \\
\text { others addressing things, documents and } \\
\text { systems. Across these definitions, } \\
\text { authentication is through processes that }\end{array}$ \\
\hline
\end{tabular}

5 UNCITRAL, Promoting confidence in electronic commerce: legal issues on international use of electronic authentication and signature methods, 2009.

${ }^{6}$ Edmon Makarim, "Buku Seri Hukum Telematika; Notaris dan Transaksi Elektronik", edisi kedua, (Jakarta: Raja Grafindo Persada 2013), hal. 75. 


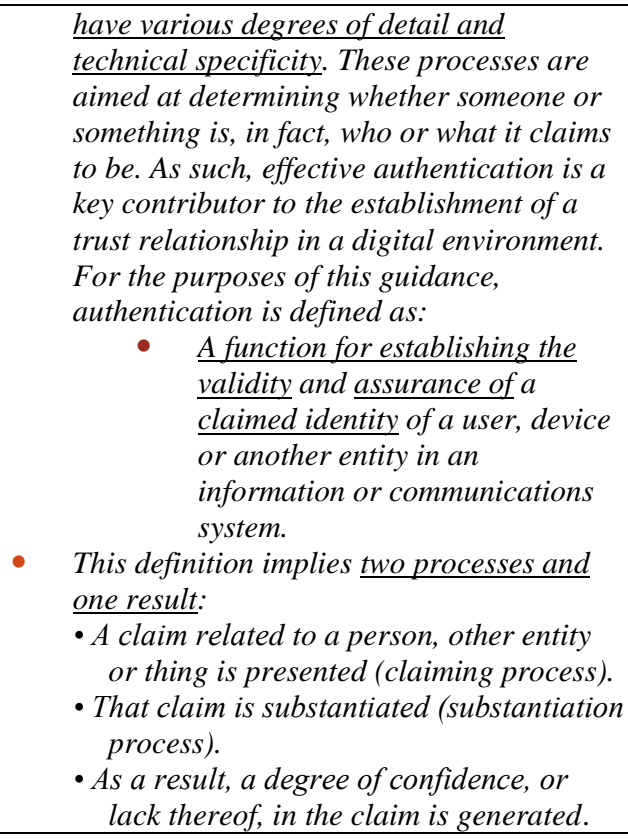

- This definition implies two processes and one result:

- A claim related to a person, other entity or thing is presented (claiming process).

- That claim is substantiated (substantiation process).

- As a result, a degree of confidence, or lack thereof, in the claim is generated.

Sehubungan dengan national e-authentication system, tidak dapat ditampik bahwa untuk dapat mengakses pelayanan publik diperlukan sistem pengidentifikasian subyek secara elektronik yang baik (electronic identity management/e-ID) yang dibangun atas pengembangan diperlukan sistem administrasidata kependudukan yang baik pula. Menurut Thierry Nabeth pembicaraan tentang identitas, setidaknya akan berbicara kedalam dua perspektif, yakni: (i) pendekatan stuktural tentang sesuatu informasi yang merujuk kepada atribusi karakteristik diri seseorang; (ii) pendekatan proses yang meminta seseorang untuk mengungkapkan informasi dirinya berikut penggunaan informasinya. ${ }^{7}$ Melengkapi hal itu, juga terdapat pandangan tentang sejauhmana informasi tersebut menjelaskan seseorang, apakah secara implisit ataukah secara eksplisit. Selain itu ada juga pandangan yang ketiga yakni (iii) perlu juga dilihat apakah yang bersangkutan memiliki kontrol atas informasi tersebut Sistem Manajemen Identitas (identity management system/IMS) yang baik tentunya akan memperhatikan ketiga faktor di atas.

Identity Management System (IMS), or systems that integrate an IMS component, use a variety of attributes to represent (model) a person and to later manage that person's information. For instance attributes can be used to represent the identifiers of a person (such as name or pseudonym), biological characteristic (gender, hair, color), location (permanent address o geo-location at a given time), competence (diploma, skills), social characteristics

${ }^{7}$ Kai Rannenberg, Denis Royer, et al, ed., "The Future of Identity in the Information Society: Challanges and Opportunities", (Frankfurt: Springer, 2009), hal. 36. 
(affiliation to groups, friends), and even behaviours (personality or mood).

Di Indonesia sistem identitas nasional difasilitasi dengan pengembangan KTP secara elektronik ("e-KTP") berdasarkan Perpres No.26 Tahun 2009 tentang Penerapan KTP berbasis NIK secara Nasional sebagaimana terakir diubah dengan Perpres No.67 Tahun 2011 ("Perpres e-KTP). ${ }^{8}$ Sebagaimana dinyatakan dalam pasal 10 A bahwa KTP Elektronik merupakan KTP yang dilengkapi dengan chip berisi rekaman elektronik, dan berlaku secara nasional di seluruh wilayah Negara Kesatuan Republik Indonesia. Selanjutnya dalam pasal 10B ditegaskan bahwa E-KTP merupakan (a). Identitas resmi bukti domisili penduduk; (b). Bukti diri penduduk untuk pengurusan kepentingan yang berkaitan dengan administrasi pemerintahan; dan (c). Bukti diri penduduk untuk pengurusan kepentingan pelayanan publik di Instansi Pemerintah, Pemerintah Daerah, Lembaga Perbankan, dan Swasta yang berkaitan dengan dan tidak terbatas pada Perizinan, Usaha, Perdagangan, Jasa Perbankan, Asuransi, Perpajakan dan Pertanahan. Sebagai kontraprestasinya, maka Instansi Pemerintah, Pemerintah Daerah, Lembaga Perbankan dan Swasta wajib memberikan pelayanan bagi penduduk dengan dasar KTP Elektronik dengan tidak mempertimbangkan tempat penerbitan KTP Elektronik.

Dalam rangka menciptakan kepemilikan 1 (satu) KTP untuk 1 (satu) Penduduk diperlukan sistem keamanan/pengendalian dari sisi administrasi ataupun teknologi informasi dengan melakukan verifikasi dan validasi dalam sistem database kependudukan serta pemberian NIK. ${ }^{9}$ Terlepas kemungkinan dugaan praktek korupsi dalam penyelenggaraan e-KTP, maka kekhawatiran publik atas mutu pembangunan dan pengamanan dalam e-KTP adalah cukup beralasan karena Indonesia belum mempunyai Government Publik Key Infrastructure (Gov PKI) berikut Root-National CA serta produk kriptografi

${ }^{8}$ Pasal I angka (3) Perpres e-KTP: KTP berbasis NIK, yang selanjutnya disebut KTP Elektronik, adalah KTP yang memiliki spesifikasi dan format KTP Nasional dengan sistem pengamanan khusus yang berlaku sebagai identitas resmi yang diterbitkan oleh Instansi Pelaksana.

9 lihat Pasal 64: (1) KTP mencantumkan gambar lambang Garuda Pancasila dan peta wilayah negara Republik Indonesia, memuat keterangan tentang NIK, nama, tempat tanggal lahir, lakilaki atau perempuan, agama, status perkawinan, golongan darah, alamat, pekerjaan, kewarganegaraan, pas foto, masa berlaku, tempat dan tanggal dikeluarkan KTP, tandatangan pemegang KTP, serta memuat nama dan nomor induk pegawai pejabat yang menandatanganinya; (2) Keterangan tentang agama sebagaimana dimaksud pada ayat (1) bagi Penduduk yang agamanya belum diakui sebagai agama sesuai dengan ketentuan Peraturan Perundang-undangan atau bagi penghayat kepercayaan tidak diisi, tetapi tetap dilayani dan dicatat dalam database kependudukan; (3) Dalam KTP sebagaimana dimaksud pada ayat (1) disediakan ruang untuk memuat kode keamanan dan rekaman elektronik pencatatan Peristiwa Penting; (4) Masa berlaku KTP: a. untuk Warga Negara Indonesia berlaku selama 5 (lima) tahun; b. untuk Orang Asing Tinggal Tetap disesuaikan dengan masa berlaku Izin Tinggal Tetap; (5) Penduduk yang telah berusia 60 (enam puluh) tahun diberi KTP yang berlaku seumur hidup. 
lokal dalam penyelenggaraan sistem pengamanannya. Tampaknya hal tersebut masih dalam proses pengembangan.

Jika dikaitkan dengan keberlakuan UU ITE, maka IMS adalah selaras dengan ketentuan tentang Tanda Tangan Elektronik yang merupakan teknologi untuk melakukan pengamanan informasi dan komunikasi. Tanda Tangan Elektronik (TTE) adalah informasi elektronik untuk melakukan verifikasi dan otentikasi atas suatu informasi elektronik. TTE dalam UU ITE bersifat netral, dan dapat mengakomodir semua jenis teknologi yang ada sepanjang memenuhi standar minimum, mencakup baik Tanda Tangan Digital yang berbasiskan PKI, hasil pindai tanda tangan basah, biometrics, RFID, penggunaan tombol akseptasi yang diamankan dengan SSL, maupun teknologi-teknologi $e$ authentication lainnya.

Dalam perkembangannya di Eropa, terdapat kesepakatan di negaranegara anggota Uni Eropa bahwa penduduk Eropa berhak untuk dapat mengakses layanan publik di negara-negara tersebut. Mereka sebelumnya telah membuat kesepakatan tentang TTE yang berlaku di Eropa. Mereka mempunyai dua kategori, yakni (i) ordinary e-signature dan (ii) advanced e-signature. Dalam rangka saling mengakui dan berinteroperabilitas, Eropa tengah mengharmonisasikan penyelenggaran e-ID management ke dalam skema empat pelaku peran sebagaimana layaknya penyelenggaraan model bisnis dari credit card; yakni (i) User, (ii) Authentication Service Provider, (iii) Linking Provider, dan (iv) Network Provider.

Patut dicermati bahwa sesuai Eropa dengan karakteristiknya sebagai satu komunitas, Eropa melihat kepentingan akan interoperabilitas antara sistem sesungguhnya harus dilihat secara komperhensif tidak hanya berfokus pada sisi teknologinya saja melainkan juga kelembagaan dan aspek-aspek terkait lainnya.

The shift from the total integrated approach to interoperability development is not only a technical change, but reflects organisational, economical and social trends/requirements of the society. To succesfully tackle this very complex and highly detailed endeavour, it is necessary to develop research involving knowledge and competencies of all domains concerned (Chen 2003)..

Dalam perkembangannya di Eropa, sistem pelayanan publik dapat saling interoperable tidak hanya antar lembaga namun juga antar negara, maka merupakan suatu keniscayaan bahwa pelayanan publik melalui sistem informasi di Indonesia dapat saling ber-interoperabilitas tidak hanya antar Kementerian/Lembaga tetapi juga antar Daerah. Semula Uni Eropa hanya memberikan pedoman pengaturan (Directive) tentang penyelenggaraan esignature, namun tanggal 28 Agustus 2014 kemarin, Uni Eropa telah mengubahnya menjadi aturan yang mengikat para Negara anggotanya (EU Regulation No.910/2014 yang merupakan Repealing dari Directive 1999/93/EC) dan mengatur mengenai Electronic Identification And Trust Services For E-Transaction In The Internal Market. 
Khusus tentang e-Identification dibahas lebih dalam pada penelitian RKOI tentang National e-ID Management, sedangkan penelitian ini karena berfokus kepada Penyelenggaraan CA maka tentunya akan membahas lebih dalam chapter ketiga dari Regulasi Uni Eropa tersebut yakni mengenai "trust services". Demi kepastian untuk menjalankan regulasi ini, diamanatkan bahwa setiap Negara anggota harus membuat Supervisory Body untuk hal itu dan bekerja berdasarkan prinsip mutual agreement dan mutual recognition antara Negara anggota. Mereka juga harus menjalin mutual assistance dalam rangka exchanging good practice. Dalam rangka menjamin keamanan mereka juga harus melaporkan kepada ENISA setahun sekali tentang laporan sistem keamanan informasi dan komunikasi mereka.

Dalam trust services diuraikan tentang beberapa jenis model layanan yang dikenal, yakni: (i) electronic signatures; (ii) electronic seals; (iii) electronic time-stamps; (iv) electronic registered delivery services; (v) web-site authentication, dan (vi) electronic documents. ${ }^{10}$

Secara umum diatur bahwa setiap Trust Services Providers memiliki tanggung jawab dan kewajiban hukum yang menganut pembebanan pembuktian terbalik. Demi kepentingan melindungi internal market Eropa, mereka membedakan antara 2 jenis kwalifikasi penyelenggara, yakni (i) Qualified Trust Service Provider ${ }^{11}$ dan (ii) Non-qualified Trust Service Provider. Perbedaan keduanya adalah terletak pada dampaknya secara hukum keautentikan yakni nilai pembuktiannya didepan hukum. Bagi yang qualified, kekuatan pembuktiannya tidak akan dipertanyakan oleh hakim, sehingga lebih menjamin kepastian hukum bagi para penggunanya.

Bagi penyelenggara yang ingin memenuhi "qualified" harus dapat memenuhi standar umum teknis yang dijahitkan sebagai lampiran, yakni beberapa requirements untuk (i) qualified certificates for e-signatures; (ii) qualified e-signature creation devices; (iii) qualified for e-seals, dan (iv) qualified certificates for website authentication. Sementara bagi yang nonqualified jika ingin menjadi Qualified harus dinilai terlebih dahulu oleh Conformity Assessment Body. ${ }^{12}$

${ }^{10}$ Article 3 point (16) 'trust service' means an electronic service normally provided for remuneration which consists of: (a) the creation, verification, and validation of electronic signatures, electronic seals or electronic time stamps, electronic registered delivery services and certificates related to those services, or $(b)$ the creation, verification and validation of certificates for website authentication; or (c) the preservation of electronic signatures, seals or certificates related to those services.

${ }^{11}$ Article 3 point (20) 'qualified trust service provider' means a trust service provider who provides one or more qualified trust services and is granted the qualified status by the supervisory body.

${ }^{12}$ Article 3 point (18) 'conformity assessment body' means a body defined in point 13 of Article 2 of Regulation (EC) No 765/2008, which is accredited in accordance with that Regulation as competent to carry out conformity assessment of a qualified trust service provider and the qualified trust services it provides. 
Pengaturan Uni Eropa ini juga mengamanatkan pemerintah Negara anggota untuk membuat dan mengelola Trusted Lists bagi para penyelenggara yang qualified dan bertanggung jawab. Selain itu pengaturan ini melahirkan adanya EU Trustmarks yang khusus untuk penyelenggaraan Trust services tersebut.

Secara umum, dapat dikatakan bahwa meskipun kemungkinan teknologi tanda tangan elekronik akan selalu berkembang (PIN, biometric, dan lain sebagainya), namun yang saat ini sudah relative mapan adalah penggunaaan tanda tangan digital berikut PKI-nya. Oleh karena itu, trust model yang saat ini sudah terbangun umumnya berpijak kepada penyelenggaraan PKI. Setidaknya terdapat beberapa "trust model" dalam penerapan tanda tangan digital, yakni: (i) Strict hierarchy, (ii) distributed trust architecture, (iii) web-model, (iii) user-centrict trust, (iv) cross-certification, (v) entity naming, dan (vi) certificate path processing.

\section{Penyelenggaraan Community $\mathrm{CA}$}

Secara umum pengertian apakah yang dimaksud dengan komunitas adalah suatu lingkup pengertian masyarakat dalam arti yang luas (society at large) yang merepresentasikan adanya suatu kepentingan yang sama. Secara teknis istilah Community $C A$ belum mempunyai suatu batasan pengertian yang baku, namun lazimnya di alamatkan kepada penyelenggaraan CA untuk kepentingan komunitas baik yang dilakukan dengan memberikan certificate secara gratis maupun berbayar dan secara teknis menganut penerapan webtrust.

\begin{tabular}{|c|c|c|}
\hline KBBI & $\begin{array}{c}\text { Webster } \\
\text { Dictionary }\end{array}$ & Oxford \\
\hline $\begin{array}{l}\text { ko·mu·ni·tasn } \\
\text { kelompok } \\
\text { organisme } \\
\text { (orang dsb) yg } \\
\text { hidup dan } \\
\text { saling } \\
\text { berinteraksi di } \\
\text { dl daerah } \\
\text { tertentu; } \\
\text { masyarakat; } \\
\text { paguyuban; } \\
\text {-- desaAntr } \\
\text { komunitas yg } \\
\text { bersifat } \\
\text { kedesa- } \\
\text { desaan; }\end{array}$ & $\begin{array}{l}\text { 1: a unified body } \\
\text { of individuals: as } \\
a \text { : state, } \\
\text { commonwealth } \\
b \text { : the people with } \\
\text { common interests } \\
\text { living in a } \\
\text { particular area; } \\
\text { broadly: the area } \\
\text { itself <the } \\
\text { problems of a } \\
\text { large community> } \\
c: \text { an interacting } \\
\text { population of } \\
\text { various kinds of } \\
\text { individuals as } \\
\text { species) in a } \\
\text { common location }\end{array}$ & $\begin{array}{l}\text { A group of peopleliving in the same place } \\
\text { or having a particularcharacteristicin } \\
\text { common: } \\
\text { 1.1A group of peopleliving together and } \\
\text { practising commonownership: a community } \\
\text { of nuns } \\
1.2 \mathrm{~A} \text { particular area or place considered } \\
\text { together with its inhabitants: } a \text { rural } \\
\text { communitylocal communities } \\
1.3 \mathrm{~A} \text { body of nations or states unified by } \\
\text { commoninterests: [in names]:the European } \\
\text { Community } \\
1.4 \text { (the community) The people of a } \\
\text { district or country considered collectively, } \\
\text { especially in the context of social values } \\
\text { and } \\
\text { society:preparingprisoners for life back in } \\
\text { the community }\end{array}$ \\
\hline
\end{tabular}




\begin{tabular}{|c|c|c|}
\hline $\begin{array}{l}-- \\
\text { bakau hutan } \\
\text { komunitas yg } \\
\text { hidup di hutan } \\
\text { bakau di } \\
\text { daerah pantai; } \\
\text {-- kotaAntr } \\
\text { komunitas yg } \\
\text { bersifat } \\
\text { kekota-kotaan; } \\
\text {-- sastra } \\
\text { kelompok atau } \\
\text { kumpulan } \\
\text { orang yg } \\
\text { meminati dan } \\
\text { berkecimpung } \\
\text { dl bidang } \\
\text { sastra; } \\
\text { masyarakat } \\
\text { sastra }\end{array}$ & 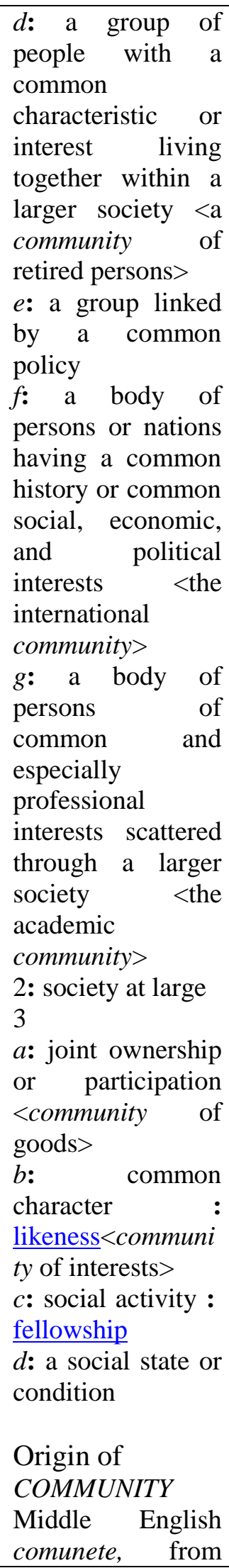 & $\begin{array}{l}1.5 \text { [as modifier] Denoting a worker or } \\
\text { resourcedesigned to serve the people of a } \\
\text { particular area:community health services } \\
2 \text { [mass noun] The condition of sharing or } \\
\text { having certain attitudes and interestsin } \\
\text { common:the sense of community that } \\
\text { organizedreligion can provide } \\
2.1 \text { [in singular] A similarity or } \\
\text { identity:the law presupposes a community } \\
\text { of interest between an employer and } \\
\text { employees } \\
2.2 \text { Jointownership } \\
\text { community of goods } \\
3 \text { EcologyA group of interdependentplants } \\
\text { or animals growing or living together in } \\
\text { natural conditions or occupying a specified } \\
\text { habitat: communities of insectivorous birds } \\
\text { Origin: late Middle English: from Old } \\
\text { Frenchcomunete, reinforced by its source, } \\
\text { Latincommunitas, from communis(see } \\
\text { common). } \\
\text { Phrases the international community: The } \\
\text { countries of the world considered } \\
\text { collectively:the policyled to } \\
\text { widespreadcondemnation from the } \\
\text { international community }\end{array}$ \\
\hline
\end{tabular}




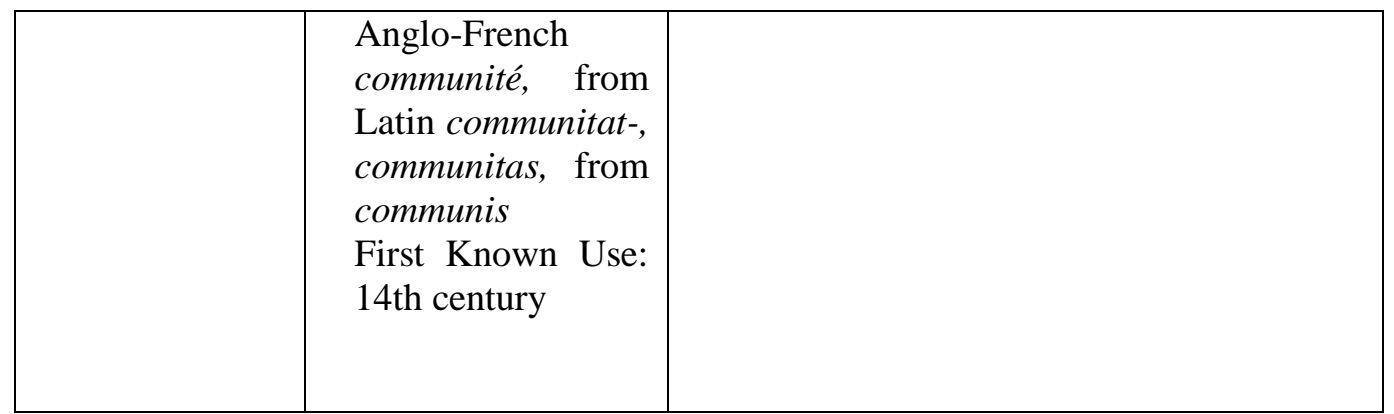

Dalam praktek sekarang ini, masih belum ditemukan Community $C A$ nasional, yang terdapat beberapa Community $C A$ di luar negeri yang memberikan jasanya secara global dengan gratis dan mengharapkan adanya donasi dari para partisipannya, diantaranya adalah OpenPGP.org serta CaCert.org

\begin{tabular}{|c|c|}
\hline \multicolumn{3}{|c}{ Open PGP } \\
\hline - OpenPGP is a non-proprietary
\end{tabular} protocol for encrypting email using public key cryptography. It is based on PGP as originally developed by Phil Zimmermann. The OpenPGP protocol defines standard formats for encrypted messages, signatures, and certificates for exchanging public keys.

- Beginning in 1997, the OpenPGP Working Group was formed in the Internet Engineering Task Force (IETF) to define this standard that had formerly been a proprietary product since 1991. Over the past decade, PGP, and later OpenPGP, has become the standard for nearly all of the world's encrypted email.

- By becoming an IETF Proposed Standard (RFC 4880), OpenPGP may be implemented by any company without paying any licensing fees to anyone.

- The OpenPGP Alliance brings companies together to pursue a common goal of promoting the same standard for email encryption and to apply the PKI that has emerged from the OpenPGP community to other non-email applications. OpenPGP Alliance members do not have to feel that they are going it alone. They can be encouraged by the power of their
- CAcert Certificate Authority that issues certificates to the public at large for free.

- CAcert's goal is to promote awareness and education oncomputer security through the use of encryption, specifically by providing cryptographic certificates.

- These certificates can be used to digitally sign and encrypt email, authenticate and authorize users connecting to websites and secure data transmission over the internet. Any application that supports the Secure Socket Layer Protocol (SSL or TLS) can make use of certificates signed by CAcert, as can any application that uses X.509 certificates, e.g. for encryption or code signing and document signatures 
numbers, to be visible to each other and work together toward a common goal, making each other stronger in the face of competing email encryption standards and competing approaches to building a Public Key Infrastructure. All this helps demonstrate to decision makers in the industry that OpenPGP really is the leading standard.

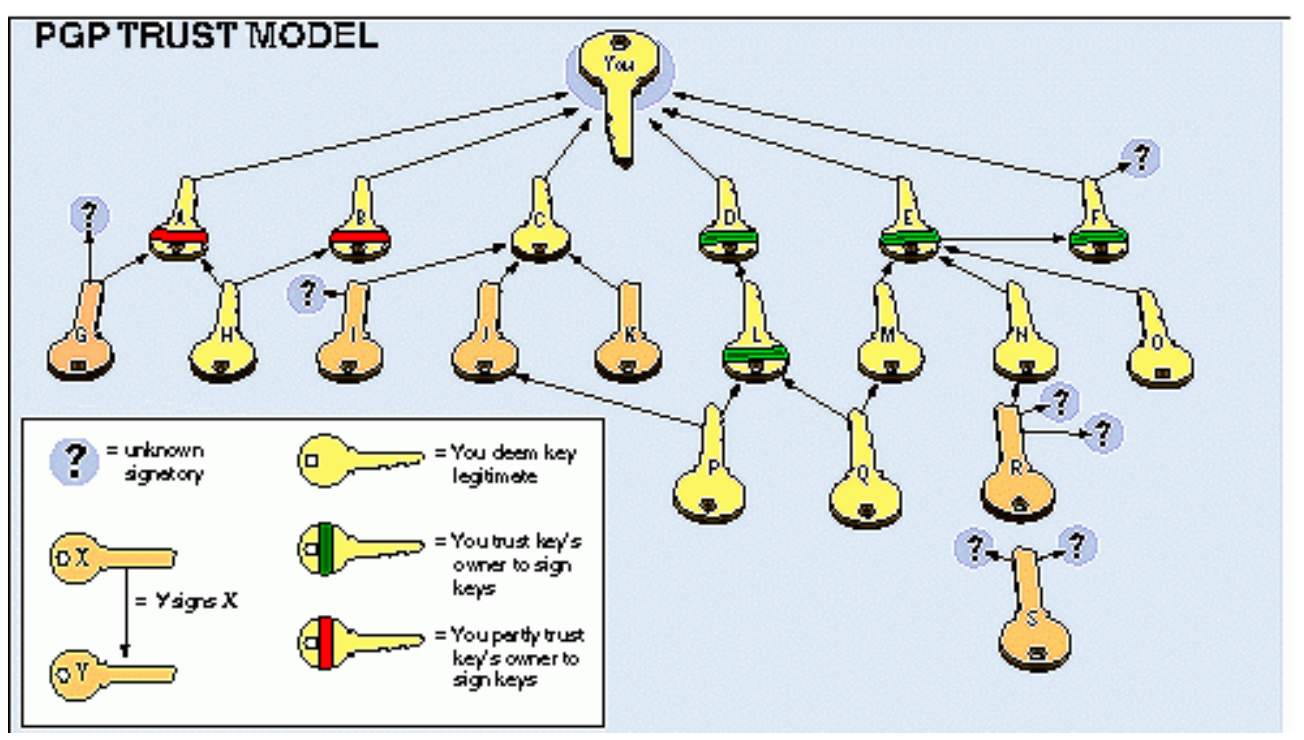

Dalam penyelenggaraannya CAcert menggunakan model trust PGP yang dikembangkan lebih lanjut dan memiliki semua kelengkapan untuk penyelengggaraan CA pada umumnya seperti antara lain; Community Agreement $^{3}$ dan Root Distribute License serta dilengkapi dengan CPS (certificate practice statement) dan CP (certificate policy).

${ }^{13}$ Dalam Community agreement didefinisikan sebagai berikut:

(i) "CAcert" means CAcert Inc., a non-profit Association of Members incorporated in New South Wales, Australia. Note that Association Members are distinct from the Members defined here.

(ii) "Member" means you, a registered participant within CAcert's Community, with an account on the website and the facility to request certificates. Members may be individuals ("natural persons") or organisations ("legal persons").

(iii) "Organisation" is defined under the Organisation Assurance programme, and generally includes corporations and other entities that become Members and become Assured.

(iv) "Community" means all of the Members that are registered by this agreement and other parties by other agreements, all being under CAcert's Arbitration. 


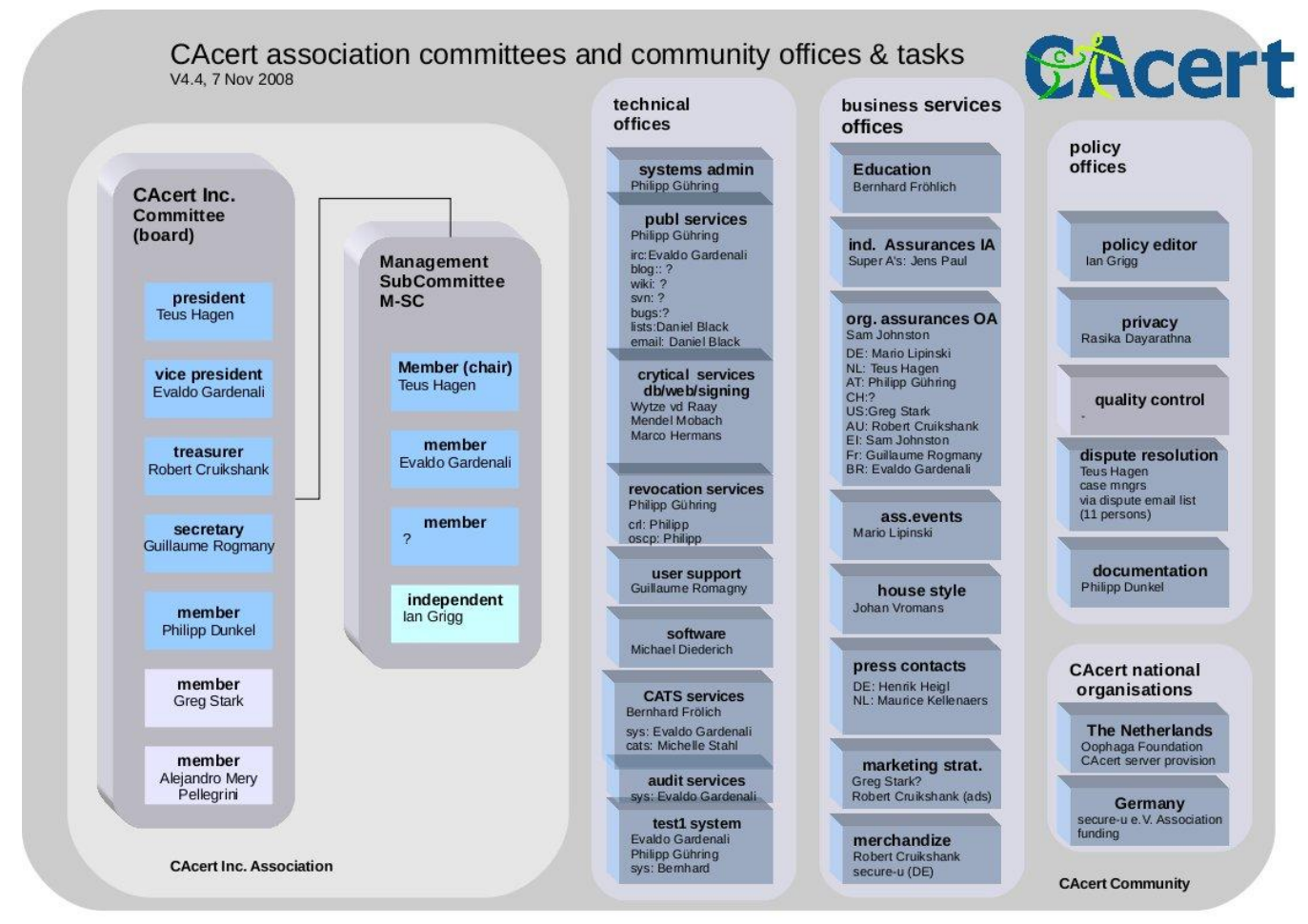

Merujuk kembali EU Directive tentang E-signature yang kini telah berubah menjadi Regulasi Uni Eropa yang baru saja dipublikasi pada tanggal 28 Agustus yang lalu. Hal tersebut ternyata berdampak materil kepada penelitian, khususnya dalam melihat kaedah untuk interoperabilitas antara CA yang dalam pengaturan tersebut dipopulerkan dengan istilah dengan "Trust Services" dimana e-signature berada dalam salah satu regulasinya.

Setelah berdiskusi dengan beberapa ahli baik dalam kalangan Desk Cybersecurity dibawah Menkopolhukam maupun kepada beberapa praktisi keamanan teknologi informasi yang terkait dengan pembangunan CA oleh pemerintah, ditemukan fakta bahwa keberadaan CA di Universitas belum dapat dikatakan menjalankan fungsi sebagai Community $C A$. Fungsi dan peran CA yang dibangun kemungkinan hanya terbatas lingkup internal. Ditengarai lebih banyak sebagai pendukung fungsi laboratorium dan belum dapat dikatakan melakukan pelayanan. Oleh karena itu, mau tidak mau maka tampaknya penelitian ini diharapkan dapat membangun dan mengeoperasikan suatu model Community $C A$ nasional yang dapat menstimulus pemberdayaan beberapa CA yang telah dikembangkan secara akademik.

Sehubungan dengan itu, mencermati pemahaman umum tentang Community $C A$, lebih banyak diutarakan kepada penyelenggaraan CA secara independen kepada masyarakat dengan model bisnis yang gratis. Kemungkinan pembiayaan dilakukan secara mandiri oleh pendiri dan mengharapkan donasi masyarakat. Umumnya dipahami bahwa Community $C A$ lebih ditujukan untuk

(v) "Non-Related Person" ("NRP"), being someone who is not a Member, is not part of the Community, and has not registered their agreement. 
menjadi sarana pembelajaran masyarakat dalam menggunakan tanda tangan digital dan sertfikat digital.

Secara umum juga dapat dikatakan bahwa Community $C A$ lebih banyak ditujukan untuk memfasilitasi resiko yang berada pada level yang rendah, dan dibangun dengan model Web Trust atau Mesh CA dimana model hierarkis yang dibangun bersifat terdistribusi secara horizontal seperti layaknya penyampaian pesan secara berantai. Dengan kata lain rantai dari trust adalah dari seseorang kepada orang lain dengan model salah satu pihak menjadi assurer atau saling mensertifikasi satu sama lain. Selain itu juga dikenal self-signing certificate namun tampaknya kurang begitu berkembang.

\section{Kerangka Hukum Nasional untuk Penyelenggaraan Community $C A$}

\begin{tabular}{|c|c|c|}
\hline & $\begin{array}{l}\text { Konstitusi dan Perundang- } \\
\text { undangan }\end{array}$ & Keterangan \\
\hline 1. & $\begin{array}{l}\text { Pasal } 28 \text { huruf C dan } 31 \text { (5) UUD } \\
\text { NRI } 1945\end{array}$ & Hak menggunakan teknologi \\
\hline 2. & UU 39/1999 Hak Asasi Manusia & $\begin{array}{l}\text { Hak penggunaan teknologi dan mencari } \\
\text { dan menyimpan informasi serta privacy }\end{array}$ \\
\hline 3. & $\begin{array}{l}\text { UU 24/2013 Administrasi } \\
\text { Kependudukan }\end{array}$ & Data pribadi harus dirahasiakan \\
\hline 4. & UU 36/1999 Telekomunikasi & $\begin{array}{l}\text { CA dapat dikategorikan sebagai salah } \\
\text { satu penyelenggaraan jasa } \\
\text { telekomunikasi multimedia }\end{array}$ \\
\hline 5. & UU 11/2008 ITE & CA harus akuntabel \\
\hline 6. & PP 82/2012 & $\begin{array}{l}\text { Pelayanan public harus menggunakan } \\
\text { CA yang berinduk kepada pemerintah }\end{array}$ \\
\hline 7. & $\begin{array}{l}\text { Draft Permen Kominfo tentang } \\
\text { Sertifikat Elektronik }\end{array}$ & CA harus berbentuk badan hukum \\
\hline 8. & $\begin{array}{l}\text { UU tentang Badan Hukum } \\
\text { (Perkumpulan berbadan hukum, PT, } \\
\text { Yayasan, dst) }\end{array}$ & $\begin{array}{l}\text { Badan hukum memerlukan suatu } \\
\text { pengesahan, sebelum pengesahan para } \\
\text { pengurus bertanggung jawab secara } \\
\text { public }\end{array}$ \\
\hline 9. & UU tentang Informasi Publik & $\begin{array}{l}\text { CA dan e-signature bukan informasi } \\
\text { publik }\end{array}$ \\
\hline 10. & UU tentang Pelayanan Publik & Penyelenggara Pelayanan Publik harus \\
\hline 11. & UU tentang Administrasi & Ketetapan administrasi Negara dapat \\
\hline
\end{tabular}




\begin{tabular}{|c|l|l|}
\hline 12. & Pemerintahan & $\begin{array}{l}\text { berbentuk elektronik namun tidak jelas } \\
\text { keamanannya }\end{array}$ \\
\hline 13. & UU Perlindungan Konsumen & $\begin{array}{l}\text { Keautentikan arsip membutuhkan CA } \\
\text { kenyamanan serta memperoleh ganti tugi } \\
\text { atas kerugian yang ditimbulkan }\end{array}$ \\
\hline 14. & UU Persaingan Usaha Yang Sehat & $\begin{array}{l}\text { Peluang Usaha membutuhkan jaminan } \\
\text { tidak atas pengecualian HKI }\end{array}$ \\
\hline 15. & Paket UU HKI yang terkait & $\begin{array}{l}\text { Jaminan perlindungan terhadap } \\
\text { penggunaan Open CA }\end{array}$ \\
\hline 16. & UU Jabatan Notaris & $\begin{array}{l}\text { Notaris harus mengamankan biometric } \\
\text { yang disimpannya } \\
\text { Notaris dapat mensertfikasi transaksi } \\
\text { elektronik (dapat berperan sebagai RA } \\
\text { atau sub-CA). }\end{array}$ \\
\hline
\end{tabular}

Selanjutnya dalam perkembangan terakhir, Kominfo telah meluncurkan pembangunan Root $C A$, dimana konsekwensinya yang berada pada level dibawahnya adalah intermediate $C A$ baik yang akan diselenggarakan oleh Pemerintah maupun yang Non Pemerintah. Berdasarkan dinamika itu, maka dapat dikatakan bahwa keberadaaan Community $C A$ bisa saja merupakan salah satu dari Intermediate $C A$ non pemerintah tersebut, sepanjang memenuhi ketentuan yang ditentukan oleh pemerintah.

\section{Penutup}

\section{Kesimpulan}

Apa yang menjadi fungsi dan peran dari Community $C A$ adalah fungsi dan peran yang independen dari masyarakat untuk sadar akan keamanan dan terbiasa untuk menggunakan produk persandian ataupun kriptografi. Oleh karenanya beberapa Community $C A$ yang ada dengan tegas menyatakan apa yang diselenggarakannya tidaklah bersifat komersial sehingga lisensi penggunaan dinyatakan dikembangkan dan dimanfaatakan sebagaimana adanya "AS IS." Berbeda dengan Private CA maka penyelenggaraan Community $C A$ tidak dilengkapi dengan kesiapan untuk pertanggungjawaban ganti rugi, sehingga dilengkapi dengan "disclaimer" tidak dapat dimintai pertanggung jawabannya kelak. Namun dalam prakteknya penyelenggaraan tetap diselenggarkan secara cermat, sehingga tetap mengandalkan physical presense dalam pelaksanaannya dan merujuk kepada para Assurer sebelumnya. 


\section{Saran}

Sesuai kontek sistem hukum nasioal, khususnya terhadap UU ITE dan Peraturan per-UU terkait lainnya, masih terbuka peluang bagi tumbuhnya Community $C A$ di Indonesia. Meskipun peluang bisnisnya belum tentu besar secara cepat namun dana masyarakt dapat digunakan (donasi) untuk mengembangkan lebih lanjut $C A$ community tersebut.

Melengkapi ketentuan dari UU-ITE dan PP-PSTE maka diperlukan suatu kerangka regulasi dan kebijakan yang dapat mengakomodir keberadaan CA yang non-government. Hal tersebut dapat dilakukan dengan melakukan pembedaan sebagaimana aturan yang telah dikembangkan oleh Uni Eropa, yakni yang memenuhi kwalifikasi dan yang belum atau tidak memenuhi kualifikasi. Mengingat bahwa keberadaan Community $C A$ masih belum jelas terlihat, maka diperlukan upaya untuk membangun model penyelenggaraan Community $C A$ yang sesuai dengan karakteristik Indonesia. 


\section{Daftar Pustaka}

Kai Rannenberg, Denis Royer, et al., (ed), The Future of Identity in the Information Society: Challanges and Opportunities, Frankfurt: Springer, 2009.

Kremer, Monique. The Netherlands from National Identity to Plural Identification, transatlantic council on Migration, March 2013.

Makarim, Edmon. Buku Seri Hukum Telematika: Notaris dan Transaksi Elektronik, edisi kedua, Jakarta: Raja Grafindo Persada, 2013.

Prins, J.E.J., et.al. Trust in Electronic Commerce: The Role of Trust from Legal, an Organizational and a Technical Point of View, Netherlands: Kluwer Law International, 2002.

UNCITRAL, Model Law for Electronic-commerce.

UNCITRAL, Model Law for Electronic-signatures. 